\title{
Implementasi Jaringan Kohonen Dalam Pengenalan Citra Huruf Aksara Jawa
}

\author{
Zulfian Azmi*, Faisal Taufik**, Bayu Susilo** \\ Program Studi Sistem Komputer, STMIK Triguna Dharma
}

\begin{tabular}{|c|c|}
\hline Article Info & ABSTRAK \\
\hline $\begin{array}{l}\text { Article history: } \\
\text { Received June } 18^{\text {th }}, 2018 \\
\text { Revised July } 17^{\text {th }}, 2018 \\
\text { Accepted Aug } 05^{\text {th }}, 2018\end{array}$ & \multirow{2}{*}{$\begin{array}{l}\text { Aksara jawa merupakan sistem penulisan yang ditulis dari kiri ke kanan. Setiap } \\
\text { aksara di dalamnya melambangkan suatu suku kata dalam vokal /a/ atau /o/, } \\
\text { yang dapat ditentukan dari posisi aksara didalam kata tersebut. Penulisan } \\
\text { aksara jawa dilakukan tanpa spasi, karena itu pembaca harus paham dengan } \\
\text { teks bacaan tersebut untuk dapat membedakan tiap kata. Dalam merancang } \\
\text { sistem pengenalan pola huruf aksara jawa tengah menggunakan metode } \\
\text { kohonen dibutuhkan pengolahan citra yang berfungsi untuk mengubah citra } \\
\text { menjadi array biner. Dan sistem dapat diimplementasikan pada aplikasi yang } \\
\text { berbasis sistem mobile. }\end{array}$} \\
\hline $\begin{array}{l}\text { Keyword: } \\
\text { Kohonen } \\
\text { Aksara Jawa } \\
\text { Android }\end{array}$ & \\
\hline & $\begin{array}{r}\text { Copyright }{ }^{(0)} 2018 \text { STMIK Triguna Dharma. } \\
\text { All rights reserved. }\end{array}$ \\
\hline $\begin{array}{ll}\text { First Author } & \\
\text { Nama } & \text { : Zulfian Az } \\
\text { Program Studi } & \text { : Sistem Kor } \\
\text { Email } & :\end{array}$ & K Triguna Dharma \\
\hline
\end{tabular}

\section{PENDAHULUAN}

Banyak hal yang menyebabkan Aksara Jawa ini dilupakan diantaranya adalah masyarakat kita lebih condong senang meniru budaya daripada budaya asli kita sendiri dan perkembangan teknologi dimasa sekarang ini banyak menggunakan bahasa asing sehingga aksara jawa tengah ini mulai banyak dilupakan masyarakat khususnya di kalangan para pemuda. Selain itu aksara jawa ini tidak digunakan untuk tujuan sehari-hari, kurangnya para ahli yang mampu untuk menggunakan serta mengajarkan aksara jawa tersebut ke orang lain atau anak didik. Sebagai salah satu warisan budaya Indonesia, aksara ini perlu dilestarikan agar dapat memperkokoh budaya bangsa yang akan mengharumkan nama Indonesia.

Salah satu hal yang dapat dilakukan adalah dengan mengajarkan dan mengenalkan kembali aksara jawa kepada masyarakat, khususnya kalangan anak muda. Maka dari itu untuk menarik minat generasi muda, dibutuhkan aplikasi pembelajaran untuk mengenali huruf aksara jawa tengah. Untuk itu diperlukan sebuah jaringan syaraf tiruan yang dapat membantu untuk mengenali pola tulisan aksara jawa Tengah. Salah satu metode yang terdapat pada jaringan syaraf tiruan untuk mengenali pola tulisan aksara jawa Tengah dengan menggunakan metode Kohonen. Metode ini merupakan suatu metode yang banyak digunakan untuk pengenalan suatu pencitraan. Di dalam suatu proses character recognition yang mempunyai basis metode kohonen tidak terdapat hidden layer seperti pada kebanyakan metode character recognition lain yang memungkinkan jalannya proses pengenalan karakter menjadi lebih cepat dibandingkan dengan metode supervised yang memiliki hidden layer.

\section{LANDASAN TEORITIS}

\subsection{Aksara Jawa}

Aksara jawa ialah sistem penulisan abugida yang ditulis dari kiri ke kanan. Setiap aksara di dalamnya melambangkan suatu suku kata dalam vokal /a/ atau /o/, yang dapat ditentukan dari posisi aksara didalam kata tersebut. Penulisan aksara jawa dilakukan tanpa spasi, karena itu pembaca harus paham dengan teks bacaan tersebut untuk dapat membedakan tiap kata. Selain itu dibanding dengan alfabet Latin, aksara jawa juga kekurangan tanda baca dasar, seperti titik dua, tanda kutip, tanda tanya, tanda seru, tanda hubung.

\subsection{Kohonen}

Jaringan Kohonen merupakan salah satu teknik Neural Network. Pada jaringan ini neuron-neuron pada suatu lapisan akan menyusun dirinya sendiri berdasarkan nilai input tertentu dalam suatu cluster. Dalam proses 
penyusunan diri, cluster yang dipilih sebagai pemenang adalah cluster yang mempunyai vector bobot paling cocok dengan pola input (memiliki jarak yang paling dekat).(T.Sutojo.2010)

Langkah-langkah yang digunakan dalam algoritma adalah sebagai berikut:

1. Langkah pertama Inisialisasi pembobotan $\mathrm{w}_{\mathrm{ij}}$ dengan nilai random. Menset parameter learning rate $(\alpha)$, pengurangan learning rate $(\beta)$ dan MaxEpoch.

2. Langkah kedua Apabila kondisi selesai belum terpenuhi, lakukan langkah berikut :

a. Untuk tiap $\mathrm{j}(\mathrm{j}=1, \ldots \mathrm{n})$, hitung:

$$
D(j)=\sum_{i-1}^{n}\left(x_{i}-w_{j}\right)^{2}
$$

b. Cari indexs j yang membuat $\mathrm{D}(\mathrm{j})$ bernilai minimum.

c. Lakukan perbaikan nilai $\mathrm{w}_{\mathrm{ij}}$ dengan nilai tertentu, yaitu: wij(baru) $=\mathrm{w}_{\mathrm{ij}}(\mathrm{lama})+\alpha\left(\mathrm{x}_{\mathrm{i}}-\mathrm{w}_{\mathrm{ij}}(\mathrm{lama})\right)$

d. Update learning rate

e.Cek kondisi kondisistopnya, simpan bobot akhir.

\section{ANALISIS DAN HASIL}

Berikut ini adalah contoh huruf aksara jawa tengah yang sudah diubah dalam bentuk 400 bit biner. Huruf ini akan dijadikan sebagai contoh pelatihan dan pengujian menggunakan algoritma Kohonen.

Iterasi ke-1

$\mathrm{x}-1=(0,5-1)^{2}+(0,5-1)^{2}+(0,5-1)^{2}+\ldots+(0,5-1)$

${ }^{2}=100,0$

$\mathrm{x}-2=(0,5-1)^{2}+(0,5-1)^{2}+(0,5-1)^{2}+\ldots+(0,5-1)^{2}=$ 100,0

$\mathrm{x}-3=(0,5-1)^{2}+(0,5-1)^{2}+(0,5-1)^{2}+\ldots+(0,5-1)^{2}=$ 100,0

$\mathrm{X}-4=(0,5-1)^{2}+(0,5-1)^{2}+(0,5-1)^{2}+\ldots+(0,5-1)^{2}=$ 100,0

$\mathrm{x}-5=(0,5-1)^{2}+(0,5-1)^{2}+(0,5-1)^{2}+\ldots+(0,5-1)^{2}=$ 100,0

$\mathrm{x}-6=(0,5-1)^{2}+(0,5-1)^{2}+(0,5-1)^{2}+\ldots+(0,5-1)^{2}=$ 100,0

$\mathrm{x}-7=(0,5-1)^{2}+(0,5-1)^{2}+(0,5-1)^{2}+\ldots+(0,5-1)^{2}=$ 100,0

$\mathrm{x}-8=(0,5-1)^{2}+(0,5-1)^{2}+(0,5-1)^{2}+\ldots+(0,5-1)^{2}=$ 100,0

$x-9=(0,5-1)^{2}+(0,5-1)^{2}+(0,5-1)^{2}+\ldots+(0,5-1)^{2}=$ 100,0

karena semua cluster memiliki jarak yang sama maka pemenangnya adalah cluster yang awal yaitu cluster ke1

perbarui cluster ke-1 dan tetangganya $(2,4,5)$

\begin{tabular}{|c|c|}
\hline $\begin{array}{c}\text { Huruf aksara Jawa } \\
\text { Tengah }\end{array}$ & $\begin{array}{c}\text { Bentuk Biner Matrik 20 } \\
\text { x 20 }\end{array}$ \\
\hline & 1111111111111111111 \\
& 1110011111111110011 \\
& 11000001111110000001 \\
& 10110001111100110001 \\
& 10111001111001110001 \\
& 10111001111110110001 \\
& 10111001111110110001 \\
& 10111001111110110001 \\
& 10111001111110110001 \\
& 10111001111110110001 \\
& 10111001111110110001 \\
& 10111001111110110001 \\
& 10111001111110110001 \\
& 10111001111110110001 \\
& 10111001111110110001 \\
& 10111001111110110001 \\
& 10111001111110110001 \\
& 10111000111001110001 \\
& 10111000000011110001 \\
& 111111111111111111 \\
\hline
\end{tabular}

Bobot $(1,1)=0,50+0,60(1-0,50)=0,80$

Bobot $(1,2)=0,50+0,60(1-0,50)=0,80$

$\operatorname{Bobot}(1,3)=0,50+0,60(1-0,50)=0,80$

$\operatorname{Bobot}(1,4)=0,50+0,60(1-0,50)=0,80$

$\operatorname{Bobot}(1,5)=0,50+0,60(1-0,50)=0,80 \ldots$.sampai dengan

$\operatorname{Bobot}(1,400)=0,50+0,60(1-0,50)=0,80$

Setelah dilakukan hingga 20 iterasi maka di dapatkan bobot akhir $=0,81$. Maka langkah selanjutnya adalah perbarui learning rate :

Learning Rate $=0.81 * 0.6=0.486$ 
Selanjutnya lakukan proses pengujian dari huruf "Wa" merupakan cluster 1 dan bukun huruf "WA" yang merupakan cluster 2 .

Untuk proses pengujian pola huruf baru yang akan dikenali yaitu dengan cara menghitung nilai jarak setiap input terhadap Cluster(j):

Input data Huruf baru(x) :

$$
\underset{D}{D(j)}=\sum_{i=1}^{n}\left(w_{i j}-x_{i}\right)^{2}
$$

111111111111111111111110011111111111001111000001111110000001110100011111001100011101100 111100111000111011001111110110001110110011111101100011101100111111011000111011001111110 110001110110011111101100011101100111111011000111011001111110110001110110011111101100011 101100111111011000111011001111110110001110110011111011100011101100111101111000111011000 1101111100011101100000111111000100011111111111111111

Jarak pada :

cluster ke-1 $=(1,0-1)^{2}+(1,0-1)^{2}+(1,0-1)^{2}+\ldots+(1,0-1)^{2}=47,5$

cluster ke-2 $=(1,0-1)^{2}+(1,0-1)^{2}+(1,0-1)^{2}+\ldots+(1,0-1)^{2}=47,0$

cluster ke-3 $=(0,5-1)^{2}+(0,5-1)^{2}+(0,5-1)^{2}+\ldots+(0,5-1)^{2}=100,0$

cluster ke-4 $=(1,0-1)^{2}+(1,0-1)^{2}+(1,0-1)^{2}+\ldots+(1,0-1)^{2}=46,2$

cluster ke-5 $=(1,0-1)^{2}+(1,0-1)^{2}+(1,0-1)^{2}+\ldots+(1,0-1)^{2}=44,5$

cluster ke-6 $=(0,5-1)^{2}+(0,5-1)^{2}+(0,5-1)^{2}+\ldots+(0,5-1)^{2}=100,0$

cluster ke-7 $=(0,5-1)^{2}+(0,5-1)^{2}+(0,5-1)^{2}+\ldots+(0,5-1)^{2}=100,0$

cluster ke- $8=(0,5-1)^{2}+(0,5-1)^{2}+(0,5-1)^{2}+\ldots+(0,5-1)^{2}=100,0$

cluster ke-9 $=(0,5-1)^{2}+(0,5-1)^{2}+(0,5-1)^{2}+\ldots+(0,5-1)^{2}=100,0$

Setelah melakukan proses pelatihan data baru, ternyata data tersebut lebih dekat terhadap cluster 1 dibanding cluster 2 maka data tersebut adalah huruf "Wa".

Tampilan Home pada system berbasis android yang, merupakan tampilan awal dari aplikasi. Di tampilan ini terdapat sebuah tombol untuk membuka menu.

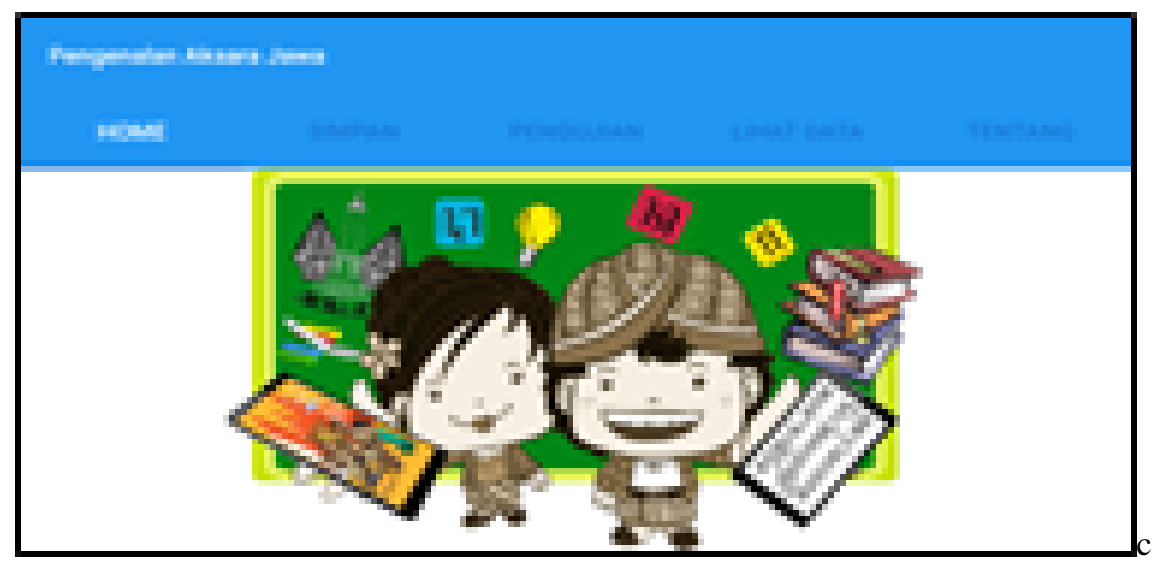

Gambar 1Tampilan Home

Tampilan data berfungsi untuk memproses huruf yang sudah dilatih. Huruf tersebut dapat dihapus. Ketika dipilih hurufnya maka akan tampil option lihat data,hapus dan cancel.

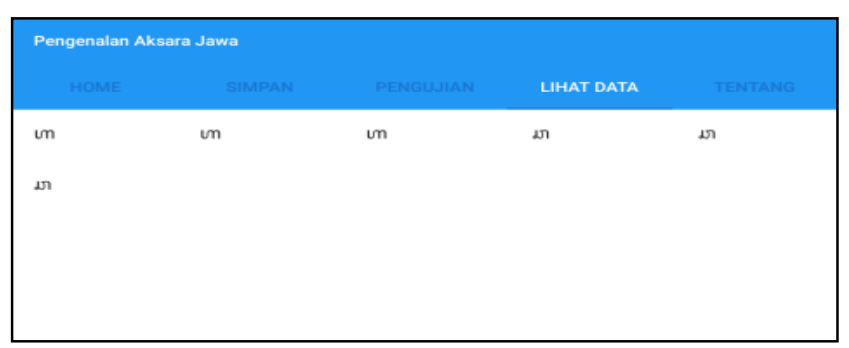

Gambar 2 Tampilan Data 
Pada tampilan ini merupakan halam untuk menguji sebuah huruf akasara jawa apakah dikenali sesuai dengan

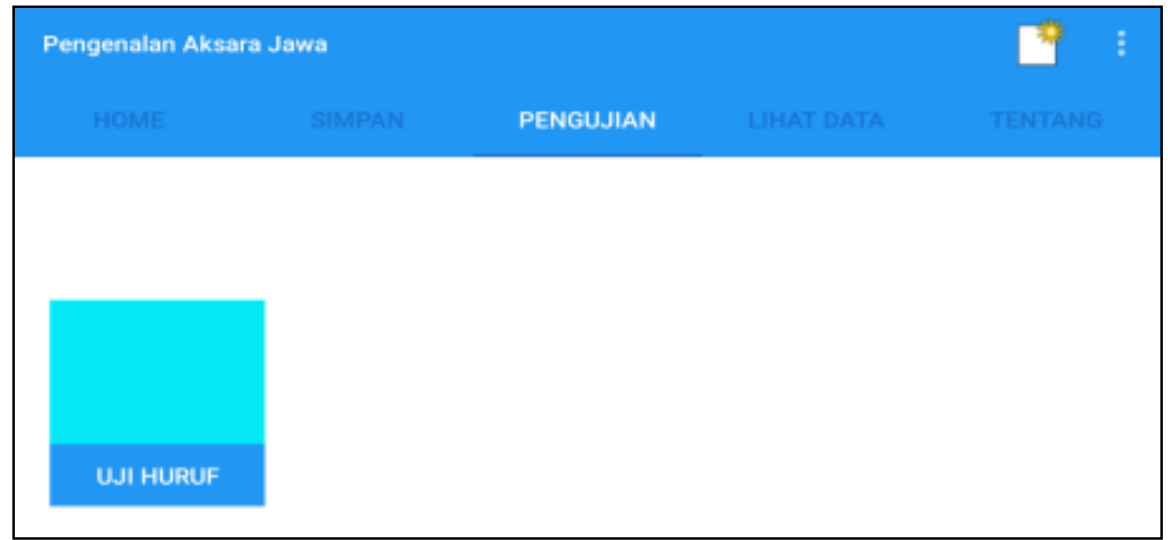

Gambar 3. Form Pengujisn

\section{KESIMPULAN}

Dari hasil penelitian yang dilakukan maka dapat di ambil beberapa kesimpulan sebagai berikut :

1 Kohonen dapat mengenali perbedaan huruf aksara jawa tengah dengan cara menghitung jarak antara huruf tersebut dengan huruf yang sudah dikelompokkan pada saat pelatihan.

2 Dalam merancang sistem pengenalan pola huruf aksara jawa tengah menggunakan metode kohonen dibutuhkan pengolahan citra yang berfungsi untuk mengubah citra menjadi array biner, dimana array biner ini yang akan di hitung menggunakan algoritma kohonen.

3 Cara kerja metode kohonen pada sistem pengenalan pola huruf aksara jawa tengah yaitu dengan cara mengelompokkan semua huruf aksara jawa tengah yang sama, sehingga apabila ditemukan huruf yang sama tetapi memiliki bentuk penulisan yang berbeda kohonen masih dapat mengenalinya.

$4 \quad$ Sistem dapat diimplementasikan pada aplikasi yang berbasis sistem operasi android (mobile).

\section{DAFTAR PUSTAKA}

Cahyo, D. H., \&Pujiyanta, A. 2013. Media PembelajaranJarigan Saraf Tiruan MetodeKohonen Berbasis Multimedia. JurnalSarjana Teknik Informatika1(1): 51-59.

Everson M. 2013. Revised Final Proposal For Encoding The Lontara (Buginese) script in the Ucs. International Organizing For Standardization Organisation Internationale de Normalisation N2588: 1 11 .

Puspitaningrum, D. 2006. Pengantar Jaringan Saraf Tiruan. Yogyakarta. Andi

Irwansyah,E,. \& Faisal, M. 2015. Advanced Clustering Teori dan Aplikasi (1 ed.). Yogyakarta: Deepublish. Afrianto, Teguh (2017) Segmentasi Aksara Pada Tulisan Aksara Jawa Menggunakan Adaptive Threshold. STIKI Infromatika Jurnal, 7(01)1-2

\section{BIOGRAFI PENULIS}

Zulfian Azmi, ST, M.Kom, Pria kelahiran Medan 16 Juni 1973 saat ini beliau menjabat
sebagai Wakil Ketua I Bidang Akademik STMIK Triguna Dharma, beberapa mata
kuliha diampu yaitu : Kecerdasan Buatan, Mikrokontroler, Pemrograman dan Jaringan
komputer. Tamat Strata 1 Universitas Sumatera Utara, Tamat Strata 2 Univeristas Putra
dan saat ini sedang menjalani program Doktoral di Universitas Sumatera Utara.

